\title{
Improving water use efficiency in grain production of winter wheat and summer maize in the North China Plain: a review
}

\author{
Xiying ZHANG (凶) ${ }^{1}$, Wenli QIN ${ }^{1,2}$, Juanna XIE ${ }^{1,2}$ \\ 1 The Center for Agricultural Resources Research, Institute of Genetics and Developmental Biology, The Chinese Academy of Sciences, \\ Shijiazhuang 050021, China \\ 2 University of Chinese Academy of Sciences, Beijing 100094, China
}

\begin{abstract}
Reducing irrigation water use by improving water use efficiency (WUE) in grain production is critical for the development of sustainable agriculture in the North China Plain (NCP). This article summarizes the research progresses in WUE improvement carried out at the Luancheng station located in the Northern part of NCP for the past three decades. Progresses in four aspects of yield and WUE improvement are presented, including yield and WUE improvement associated with cultivar selection, irrigation management for improving yield and WUE under limited water supply, managing root system for efficient soil water use and reducing soil evaporation by straw mulch. The results showed that annual average increase of $0.014 \mathrm{~kg} \cdot \mathrm{m}^{-3}$ for winter wheat and $0.02 \mathrm{~kg} \cdot \mathrm{m}^{-3}$ in WUE were observed for the past three decades, and this increase was largely associated with the improvement in harvest index related to cultivar renewal and an increase in chemical fertilizer use and soil fertility. The results also indicated that deficit irrigation for winter wheat could significantly reduce the irrigation water use, whereas the seasonal yield showed a smaller reduction rate and WUE was significantly improved. Straw mulching of summer maize using the straw from winter wheat could reduce seasonal soil evaporation by $30-40 \mathrm{~mm}$. With new cultivars and improved management practices it was possible to further increase grain production without much increase in water use. Future strategies to further improve WUE are also discussed.
\end{abstract}

Keywords harvest index, cultivar selection, deficit irrigation, root water uptake, straw mulching

Received December 13, 2015; accepted March 8, 2016

Correspondence: xyzhang@sjziam.ac.cn

\section{Introduction}

China is facing a water crisis due to water shortages and water pollution. The increasing water scarcity and the competition from other sectors have put irrigation under great pressure ${ }^{[1]}$. Grain production, a sector heavily dependent on irrigation, is facing unprecedented challenges. Further increase in grain production to meet the requirements of a growing population would put further pressures on water resources in China in the future and worsening water shortages threaten China's Food Security. Producing more food with less water by increasing water use efficiency (WUE) or water productivity is an important measure to solve the water crisis both in China and around the world ${ }^{[2]}$.

Water use efficiency (WUE) at yield level is defined as grain produced per unit water consumption. The recent average WUE of the three main grain crops in China has been $0.85 \mathrm{~kg} \cdot \mathrm{m}^{-3}$ for rice, $1.01 \mathrm{~kg} \cdot \mathrm{m}^{-3}$ for wheat and $1.51 \mathrm{~kg} \cdot \mathrm{m}^{-3}$ for maize ${ }^{[3]}$. A higher WUE results in either the same production from less water resources, or a higher production from the same water resources. Zwart and Bastiaanssen ${ }^{[4]}$ reviewed 84 literature sources with results of experiments within the past 25 years, and they found that the average WUE of wheat, rice and maize was 1.09 , 1.09 and $1.80 \mathrm{~kg} \cdot \mathrm{m}^{-3}$, respectively, around the world. Thus, the overall WUE in grain production in China fell behind the world level. Zwart and Bastiaanssen ${ }^{[4]}$ also reported there was a large range of WUE (wheat, $0.6-1.7 \mathrm{~kg} \cdot \mathrm{m}^{-3}$; rice, $0.6-1.6 \mathrm{~kg} \cdot \mathrm{m}^{-3}$; and maize, $1.1-2.7 \mathrm{~kg} \cdot \mathrm{m}^{-3}$ ). The gap between the current WUE in China with the maximum WUE reported by Zwart and Bastiaanssen ${ }^{[4]}$ was quite large, and thus offers tremendous opportunities for maintaining or increasing agricultural production using less water, in particular by improving WUE for grain production while reducing irrigation water use. 
Improving WUE for grain production in the North China Plain (NCP) is an urgent priority. NCP is one of the most important grain production areas in China. The rich soil and climate are favorable for growing winter wheat and summer maize as a double cropping system. The mean annual rainfall is about $450-600 \mathrm{~mm}$. About $70 \%$ of the rainfall occurs from July to September, the growing season for maize. Rainfall during the winter wheat growing season, which is from October to May of the following year, ranges from about $60-180 \mathrm{~mm}$. Supplemental irrigation is required to support wheat production, as the consumptive water use by winter wheat is about $430-500 \mathrm{~mm}^{[5,6]}$. Farmers in this region generally irrigate winter wheat three or four times each season. They also irrigate maize once to three times per season. Farmers have pumped significant amounts of groundwater in recent years, contributing to a significant overdraft problem. The groundwater level has declined rapidly with a rate over $1 \mathrm{~m}$ per year in some parts of NCP. A recent report on this water shortage problem was entitled "Water shortages loom as Northern China's aquifers are sucked dry" [6].

Improving WUE in grain production in NCP is critical for the sustainable development of agricultural irrigation in this region. An increase in WUE can be achieved by improved agronomic practices, breeding and management ${ }^{[7-12]}$. This article summarized the research progresses in WUE improving carried out at the Luancheng EcoAgro-Experimental Station of the Chinese Academy of Sciences in the NCP and discusses future strategies to further improve WUE.

\section{Practices to improve grain yield and WUE}

2.1 Changes in crop water use, yield and WUE during the past three decades

Evapotranspiration $(E T)$ is an important component of the water cycle on the field, regional and global scale. It is affected by both atmospheric demands and surface conditions. A 30-year irrigation experiment on winter wheat and summer maize was used to analyze the impacts of climatic factors and crop productivity on ET at a typical site in the $\mathrm{NCP}^{[10]}$. The results showed that reference evapotranspiration $\left(E T_{0}\right)$ was relatively constant. However, the actual seasonal $E T$ of winter wheat and maize under well-watered condition gradually increased from the 1980s to the 2000s. The mean seasonal ET was 401.4,
417.3 and $458.6 \mathrm{~mm}$ for winter wheat, the corresponding average grain yield (GY) was 4790, 5501 and $6685 \mathrm{~kg} \cdot \mathrm{hm}^{-2}$ in the $1980 \mathrm{~s}, 1990 \mathrm{~s}$ and $2000 \mathrm{~s}$, respectively. The mean seasonal ET for maize was $375.7,381.1$ and $396.2 \mathrm{~mm}$ with GY of 5054, 7041 and $7874 \mathrm{~kg} \cdot \mathrm{hm}^{-2}$, respectively, for the three periods. The results showed that the increase in $E T$ was not in proportion to the increase in GY, with the former being smaller than the latter. The larger increase in GY compared to ET resulted in a significant improvement in WUE in the past three decades $(P<0.01)$ for the two crops (Table 1). The average WUE for winter wheat and maize during the 30 years period was 1.32 and $1.72 \mathrm{~kg} \cdot \mathrm{m}^{-3}$, respectively. It was around $1.19,1.31$ and $1.45 \mathrm{~kg} \cdot \mathrm{m}^{-3}$ for winter wheat during the 1980s, 1990s and 2000s, respectively. Average WUE was $1.35,1.84$ and $1.98 \mathrm{~kg} \cdot \mathrm{m}^{-3}$ for maize during the 1980 s, 1990s and 2000s, respectively. There was an annual increase of $0.014 \mathrm{~kg} \cdot \mathrm{m}^{-3}$ for winter wheat and $0.032 \mathrm{~kg}$ $\cdot \mathrm{m}^{-3}$ for maize. The increase in WUE was greater for maize than that for wheat, similar to the findings for yield increase.

The results showed that with new cultivars, improved soil fertility and management practices, it was possible to increase grain production without much increase in water use. This is very important for mitigating global water scarcity and at the same time meeting the food demands of a growing population.

\subsection{Yield and WUE improvement associated with cultivars and soil fertility improvement}

Introducing new cultivars (cultivar renewal) played an essential role in yield and WUE improvement in the NCP. Studies were carried out to understand the genetic gains in yield and WUE and their associated physiologic and agronomic traits for winter wheat ${ }^{[9,13]}$. Two groups of winter wheat cultivars were tested. Group 1 included 16 winter wheat cultivars that were released between 1998 and 2002, and Group 2 included 10 cultivars released between 1970 and 2000. Results showed that WUE increased substantially from 1.0 to $1.2 \mathrm{~kg} \cdot \mathrm{m}^{-3}$ for cultivars from the early $1970 \mathrm{~s}$ to $1.4-1.5 \mathrm{~kg} \cdot \mathrm{m}^{-3}$ for recently released cultivars. Even in the more recently released Group 1 cultivars there was also a variation of about $20 \%$ in yield and WUE. Most of the cultivars in both groups had similar responses to water supply. WUE was greater for lower irrigation treatments and maximum grain production was achieved with moderate water deficit.

Table 1 The changes in the average yield and water use efficiency (WUE) of winter wheat and maize for the past 30 years

\begin{tabular}{|c|c|c|c|c|}
\hline \multirow{2}{*}{ Period } & \multicolumn{2}{|c|}{ Winter wheat } & \multicolumn{2}{|c|}{ Summer maize } \\
\hline & Yield $/\left(\mathrm{kg} \cdot \mathrm{hm}^{-2}\right)$ & $\mathrm{WUE} /\left(\mathrm{kg} \cdot \mathrm{m}^{-3}\right)$ & Yield $/\left(\mathrm{kg} \cdot \mathrm{hm}^{-2}\right)$ & $\mathrm{WUE} /\left(\mathrm{kg} \cdot \mathrm{m}^{-3}\right)$ \\
\hline$\overline{1980 \mathrm{~s}}$ & 4790 & 1.19 & 5054 & 1.35 \\
\hline $2000 \mathrm{~s}$ & 6685 & 1.45 & 7874 & 1.98 \\
\hline Increase & $39.6 \%$ & $21.8 \%$ & $55.8 \%$ & $46.7 \%$ \\
\hline
\end{tabular}


The genetic gains in grain yield for cultivars released in different years were associated with increases in biomass, harvest index and kernel numbers per spike. Among the Group 1 cultivars, the ones with higher yield generally had higher WUE (Fig. 1). No significant correlations were found between WUE and physiological traits such as ash content, chlorophyll content, or relative water content among the cultivars released recently. However a significant relationship was found between stomatal conductance or ash contents and WUE or grain yield among the Group 2 cultivars. Correlations were apparent between WUE and harvest index and root:shoot ratio $(P<0.05)$ in Group 1. Earlier flowering cultivars tended to have higher grain yield and higher harvest index. In Group 2, flowering date advanced by about 4 days over the 30 years of crop breeding. The positive relationship between grain yield and WUE for all the cultivars indicated that using a higher yielding cultivar has the potential to improve WUE.

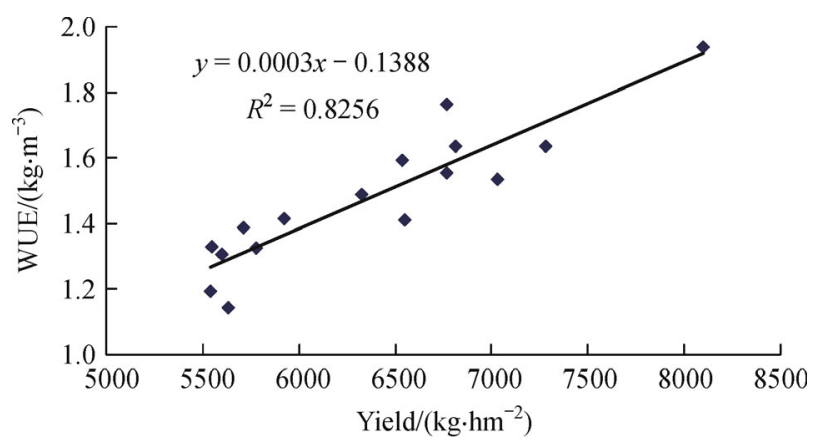

Fig. 1 Correlation of yield and water use efficiency (WUE) of winter wheat among 16 modern cultivars grown under the same condition in 2012-2013 season

Root length is an important trait in crop water use. The results from the Group 2 experiment showed that the seasonal $E T$ of earlier released cultivars was similar to that of recently released cultivars under well-watered conditions. However, ET was slightly increased from earlier to recent released cultivars under water deficit conditions, indicating high soil water depletion by recently released cultivars. Total root length decreased from earlier to recent released cultivars and was significantly correlated with plant height. The breeding of winter wheat that reduced plant height not only increased harvest index, but also reduced root size, resulting in a smaller root:shoot ratio, which favored a higher WUE. The reduction in total root length from earlier to recent released cultivars mainly occurred in the top soil profile. The results indicate that total root length is not a factor that determines soil water use; rather, the distribution of root length density through the soil profile plays more important role in soil water utilization $^{[14]}$.

The improved soil fertility in the tillage soil layer might also be one of the reasons that the reduced root growth in the top soil layer didn't affect the crop yield. Figure 2 shows the continuous increase in soil organic matter and soil $\mathrm{N}$ contents for the tillage soil layer at the experimental site for the past 30 years. The increase in soil fertility was related to the practices of returning the straw to the soil and increased utilization of chemical fertilizer. Under nutrient deprivation conditions, crops tend to increase their root growth to extend their contact with the soil to obtain more nutrients, resulting in a higher root:shoot ratio ${ }^{[15]}$. Research has shown that consumption of carbohydrates in root respiration is proportional to root size ${ }^{[16]}$. The higher consumption of carbohydrates for root growth and respiration would reduce the biomass accumulation for shoot growth and yield formation. Thus, the WUE under nutrient deficient conditions was reduced. A negative relationship was found between the root:shoot ratio and the $\mathrm{WUE}^{[17]}$. The increase in the soil fertility and nutrient input improved HI, which favored a greater WUE.

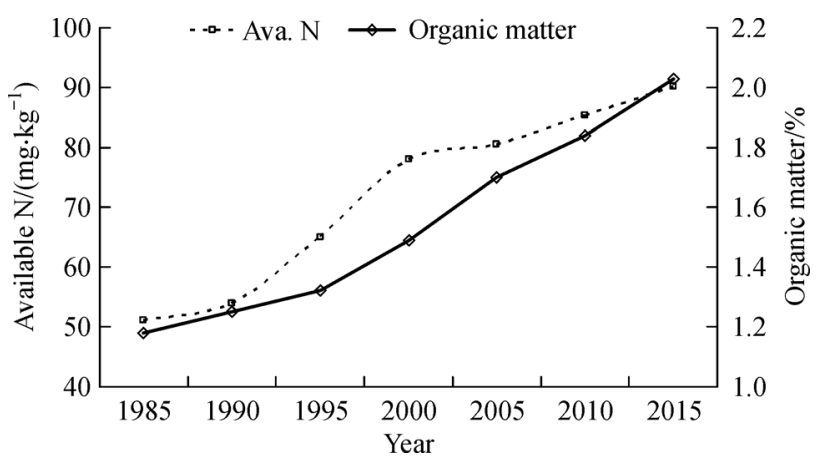

Fig. 2 The increase in soil organic matter and total $\mathrm{N}$ contents for the experimental site for the past 30 years at Luancheng station

\subsection{Irrigation management for improving yield and WUE} under limited water supply

\subsubsection{Optimized irrigation scheduling for winter wheat}

Results of six years of field experiments with winter wheat using six irrigation treatments varying from rain-fed up to five irrigations showed that dry matter production, grain yield and WUE were not linearly related to $E T$, but were best described in a quadratic curve $e^{[5,18]}$ (Fig. 3). The maximum total dry matter production at maturity was achieved at $94 \%$ of the seasonal full ET and the highest grain yield was produced at $84 \%$ of the seasonal full ET. A positive relationship was found between harvest index and dry matter remobilization during grain filling. Moderate water deficit accelerated the remobilization and transfer of dry matter from vegetative tissues to the grain, resulting in higher grain yield and WUE. The more rapid transfer of dry matter to the grain is of particular importance under the climatic conditions of the NCP where grain filling only lasts for one month because of the weather conditions.

Generally higher WUE occurred with relatively lower 


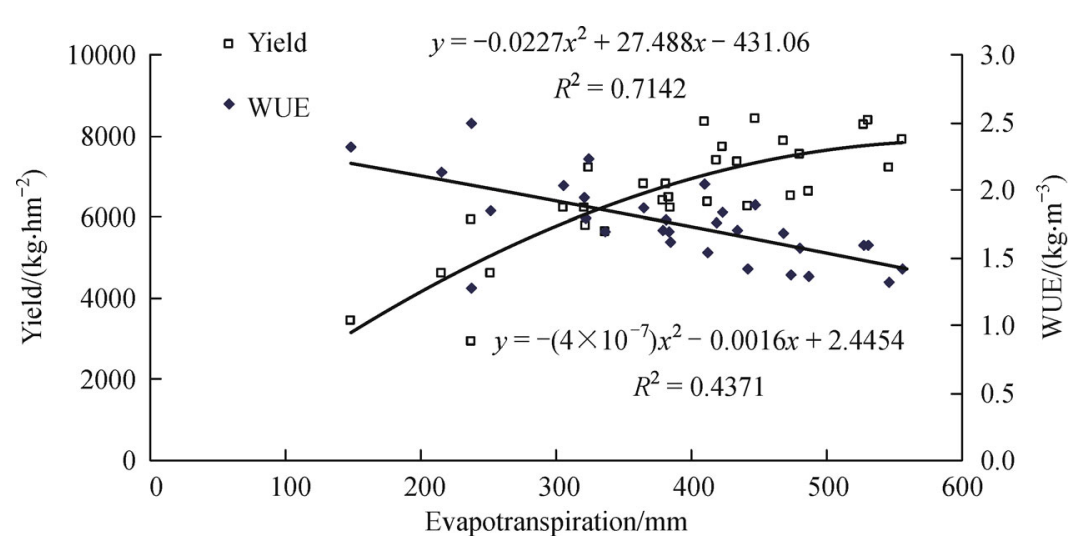

Fig. 3 The correlation of evapotranspiration with yield and water use efficiency (WUE) for winter wheat from 2010 to 2015

$E T$. The maximum WUE was achieved with a water supply of about half of potential $E T$, but yield was much reduced under this $E T$. To optimize yield while achieving a higher WUE the seasonal water consumption for winter wheat should be in the range of $250-420 \mathrm{~mm}(50 \%-84 \%$ of potential ET). With an average seasonal rainfall of $132 \mathrm{~mm}$, irrigation requirement was around $120-300 \mathrm{~mm}$.

Maximizing yield and WUE of wheat also depended on the utilization of subsoil moisture. Due to the deep root system of winter wheat and the high water holding capacity of the soil profile about $100-150 \mathrm{~mm}$ of soil stored water is available during the wheat growing season. This is equivalent to an average of $35 \%$ of the ET required to support optimum yield. The optimum seasonal irrigation amount was then around $60-140 \mathrm{~mm}$ in a normal season. Practical guidelines for scheduling irrigation of winter wheat to optimize yield and WUE were developed as follows: in wet seasons one irrigation applied at jointing stage, in normal seasons two irrigations applied at jointing and during booting to anthesis, in dry seasons three irrigations applied at jointing, booting and early milk stages $^{[18]}$. When following the guidelines, the number of irrigations that farmers would normally have been used was reduced by 1 or 2 and WUE was increased by $15 \%$ (from 1.3 to $1.5 \mathrm{~kg} \cdot \mathrm{m}^{-3}$ increased to $1.6-1.7 \mathrm{~kg} \cdot \mathrm{m}^{-3}$ ), meaning irrigation water saving could be around 60-120 mm per season.

2.3.2 Minimum irrigation strategy for double cropping of wheat and summer maize

The double cropping of winter wheat and summer maize means the NCP is intensively irrigated which resulted in the rapid depletion of aquifers and threatens the sustainability of agricultural development in the region. Field studies were carried out to investigate the possibility of growing winter wheat and maize with minimum irrigation application $(\mathrm{MI})^{[19,20]}$. The approach was to irrigate just before sowing to bring soil moisture in the upper root zone to field capacity with no further irrigation afterwards. Results over eight years showed that under MI grain yield of winter wheat was over $5000 \mathrm{~kg} \cdot \mathrm{hm}^{-2}$ and maize was over $6000 \mathrm{~kg} \cdot \mathrm{hm}^{-2}$ in most of the seasons. On average, yield was decreased by $13.9 \%$ for winter wheat and $13.3 \%$ for maize (Fig. 4), and WUE was increased by around $10 \%$ to $20 \%$ under MI compared to the normal irrigation practice.

During the MI experiments, the average seasonal ET for winter wheat was $334.7 \mathrm{~mm}$, and for maize was $319.3 \mathrm{~mm}$. The mean annual total ET of the double cropping system was $654 \mathrm{~mm}$ under MI and $850 \mathrm{~mm}$ under the normal irrigation practice. Under MI irrigation water use could be reduced annually by $200 \mathrm{~mm}$. An analysis of the long-term impact of MI on yield, based on rainfall data from 1960 to 2005 , led to the conclusion that for about half of the years the yield reduction under MI would be less than $15 \%$, one third of the years less than $10 \%$ and in one fifth of the years there would be no significant yield decrease. Even when the seasonal rainfall was extremely low, soil moisture depletion by the deep winter wheat root system contributed substantially to the seasonal ET. The dried soil profile could be replenished gradually during the following summer rainy season. The results showed that in this serious water shortage area the MI irrigation strategy might be possible. The water saved could be used for other more profitable production.

2.3.3 Optimizing the yield of winter wheat by regulating water consumption during vegetative and reproductive stages under limited water supply

A study lasting six seasons was carried out, comprising four treatments: rain-fed, single irrigation applied at sowing to obtain a good level of soil moisture at the start of crop growth (I1s), single irrigation applied during recovery to jointing (I1r) and full irrigation supplied as three irrigations (control, I3), to optimize the grain production of winter wheat under limited water supply ${ }^{[21]}$. The results showed that grain yield was significantly 

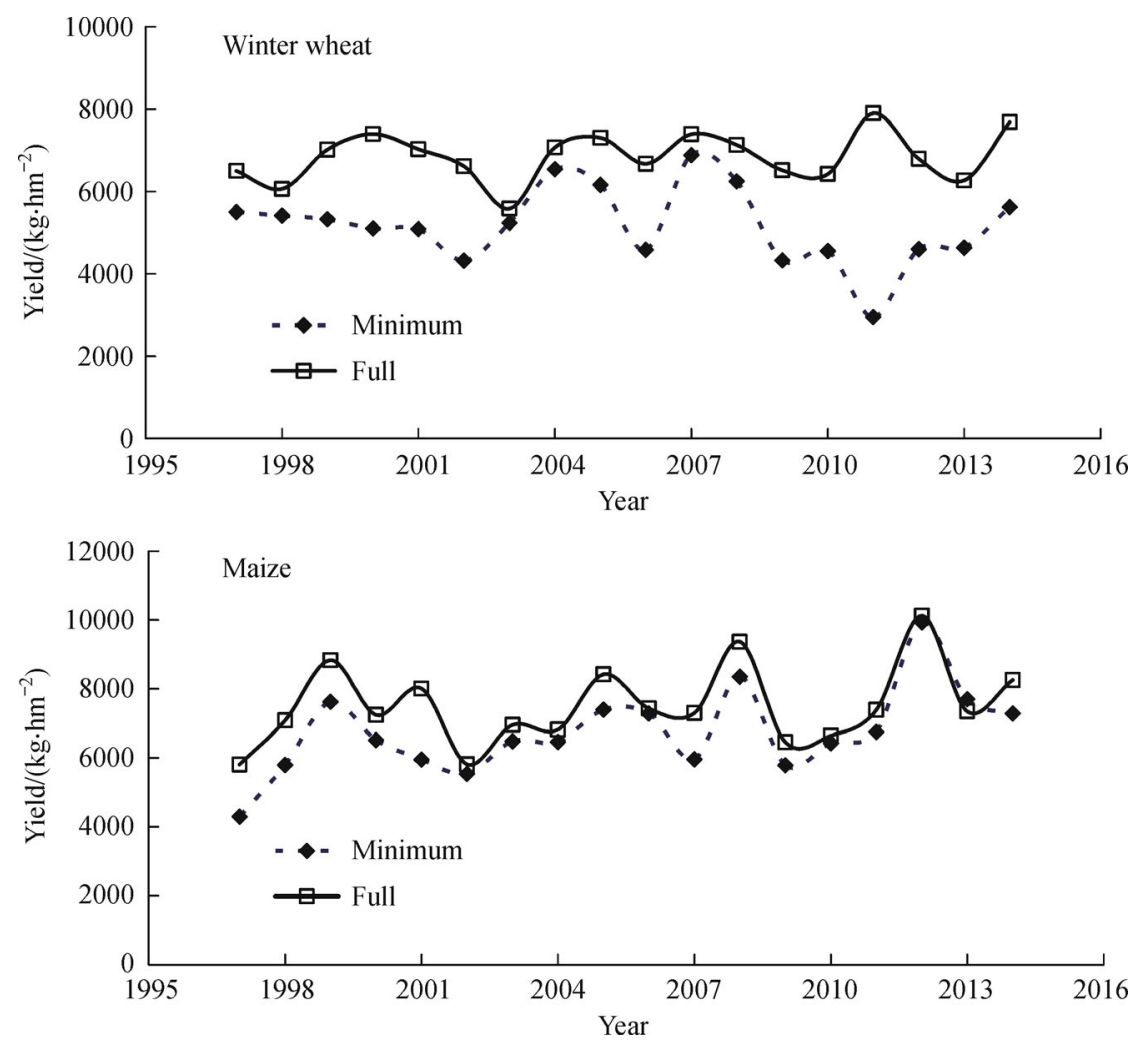

Fig. 4 The yield of winter wheat and maize under minimum irrigation as compared with the full irrigation for the past 18 years (19972015) at Luancheng station

correlated with rainfall before heading and with $E T$ after heading $(P<0.01)$ under rain-fed conditions. The average contribution of soil water stored before sowing to seasonal ET was 90, 103 and $145 \mathrm{~mm}$ for rain-fed, I1s and I1r, respectively, during the 6 seasons. A smaller root length density (RLD), which restricted the utilization of deep soil water by the crop, was one of the reasons for the lower yield with rain-fed and I1s treatments compared with the I1 $r$ treatment in dry seasons. The results also showed that the limited irrigation applied from recovery to jointing stage (Treatment I1r) significantly promoted vegetative growth and more efficient soil water use during the reproductive (post-heading) stage, resulting in a $21.6 \%$ yield increase compared with that of the I1s treatment (Table 2). Although the average yield of the I1r treatment was $14 \%$ lower than that of the full irrigation treatment, seasonal irrigation was reduced by $120-140 \mathrm{~mm}$. With smaller penalties in yield and a larger reduction in applied irrigation, I1r could be considered a feasible irrigation practice that could be used in the NCP for conservation of groundwater resources.

\subsection{Managing root system for efficient soil water use}

The monsoon climate in the NCP causes most rain to fall in the summer season, while during the winter wheat growing season (October to May), rainfall is far less than the water requirements for the crop. Therefore if the efficiency in soil water use by winter wheat can be improved, then less irrigation water would be needed. Field measurements were conducted to study soil water utilization, root growth and distribution, root water uptake by winter wheat under different irrigation treatments, and identify possible ways to improve soil water use efficiency ${ }^{[14,21,22]}$.

Root sampling results showed that winter wheat had a prolific root system with an average depth of $2 \mathrm{~m}$. Most of

Table 2 Average yield, water use (ET) and water use efficiency (WUE) of winter wheat and maize under critical stage irrigation as compared with rainfed and full irrigation from 1997 to 2015 at Luancheng station

\begin{tabular}{|c|c|c|c|c|c|c|}
\hline \multirow{2}{*}{ Irrigation treatments } & \multicolumn{3}{|c|}{ Winter wheat } & \multicolumn{3}{|c|}{ Summer maize } \\
\hline & Yield $/\left(\mathrm{kg} \cdot \mathrm{hm}^{-2}\right)$ & $E T / \mathrm{mm}$ & $\mathrm{WUE} /\left(\mathrm{kg} \cdot \mathrm{m}^{-3}\right)$ & Yield $/\left(\mathrm{kg} \cdot \mathrm{hm}^{-2}\right)$ & $E T / \mathrm{mm}$ & $\mathrm{WUE} /\left(\mathrm{kg} \cdot \mathrm{m}^{-3}\right)$ \\
\hline Rain-fed & 3372.9 & 203.1 & 1.67 & 4842.6 & 244.5 & 1.98 \\
\hline Critical stage & 5988.8 & 329.2 & 1.82 & 6750.8 & 341.2 & 1.98 \\
\hline Full irrigation & 6952.7 & 420.9 & 1.65 & 7516.1 & 448.1 & 1.68 \\
\hline
\end{tabular}


the root system was concentrated in the upper $40 \mathrm{~cm}$ of soil. Root length density in the top layer of soil $(0-20 \mathrm{~cm})$ was very high with values over $3 \mathrm{~cm} \cdot \mathrm{cm}^{-3}$. The distribution of water uptake from the soil profile under high soil moisture conditions was closely related to the distribution of root length density. When root length density was less than $0.8 \mathrm{~cm} \cdot \mathrm{cm}^{-3}$, the root was the main factor limiting the complete utilization of soil water by crops. At maturity, over $100 \mathrm{~mm}$ of available water remained in the root-zone for the rain-fed treatment, although the upper layers had already entered water deficit, since the scarcity of roots in the deep soil layers restricted the full utilization of soil water (Fig. 5). For irrigated wheat, from $40 \%$ to $50 \%$ of crop water use was from the stored soil water, and for the rain-fed wheat up to $80 \%$ of the water use was from the stored soil water in a dry season. Available stored soil water played an important role in the higher production of wheat crops in the NCP. Effective measures to increase the utilization of stored soil water could improve crop performance under conditions of limited water supply.

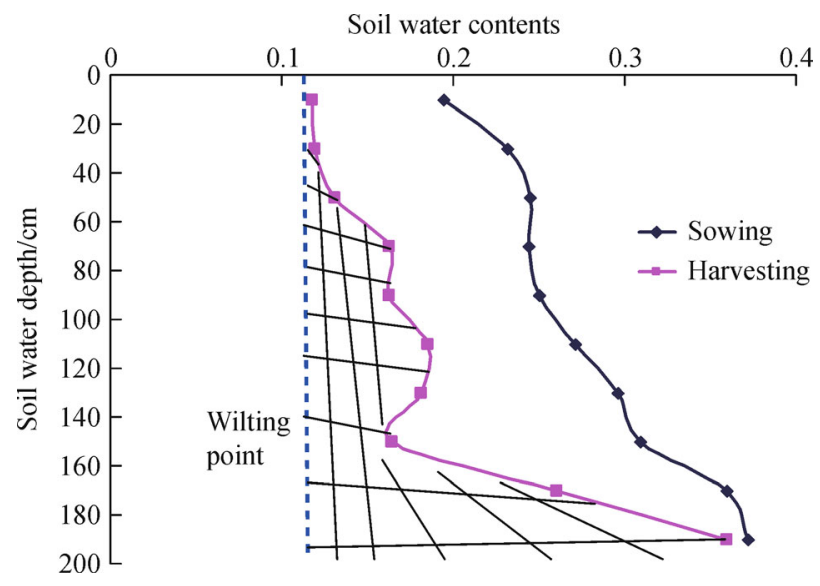

Fig. 5 The soil water contents (V/V) along the soil profile at sowing and at harvesting for winter wheat under limited water supply (The shaded area indicating there was available soil water not extracted by the roots)

Recent results showed that the bulk density was increased under the tillage layer ${ }^{[22]}$. Soil pan was becoming thicker and moving upwards with the application of minimum tillage practices in the $\mathrm{NCP}^{[22]}$. This situation significantly affected the root distribution along the soil profile ${ }^{[23]}$. The limitation to soil water use under dry condition existed in the deep soil profile where RLD was smaller. Results showed that deep tillage to break the soil pan improved root growth in the deeper soil layers that could benefit the grain production of winter wheat and maize under limited water supply ${ }^{[22]}$. Other practices such as rotation using "break crops" to break soil pan was also an effective method to encourage deep root growth of crops under dry conditions ${ }^{[24,25]}$.

\subsection{Reducing soil evaporation by mulch}

The double cropping system of winter wheat and maize in the NCP requires about $850 \mathrm{~mm}$ water annually, in which over $20 \%-30 \%$ is from soil evaporation that is generally thought non-effective for crop production ${ }^{[8]}$. Straw mulching has been widely used to conserve soil moisture. The double-cropping system of winter wheat and maize produces a large quantity of straw every year that is a good source for straw mulching. Experiments on straw mulching were carried out at Luancheng station for over ten years to investigate the effects of straw mulching on soil evaporation, soil temperature and crop production as well as WUE.

Micro-lysimeters were used to measure daily soil evaporation with and without straw mulch. Results showed that the average soil evaporation rate for mulched treatment was smaller than that of non-mulched treatment, especially in the earlier growth stages of crops when leaf area index was low (Fig. 6). Over the growing season the average soil evaporation rate was 0.52 and $1.17 \mathrm{~mm}$ per day for the mulched and non-mulched maize treatments, respectively. The results over 12 years showed that straw mulch reduced soil evaporation in maize fields by $40-50 \mathrm{~mm}$ and improved WUE by $7 \%-10 \%$. For winter wheat under straw mulching, soil evaporation was reduced by $40 \%$, averaged over five seasons. Straw mulching reduced soil evaporation about $80-100 \mathrm{~mm}$ annually. With the use of combines to harvest wheat, straw mulch could be readily applied to maize. A further benefit is the reduction in pollution from burning the straw as was commonly done by farmers in the past.

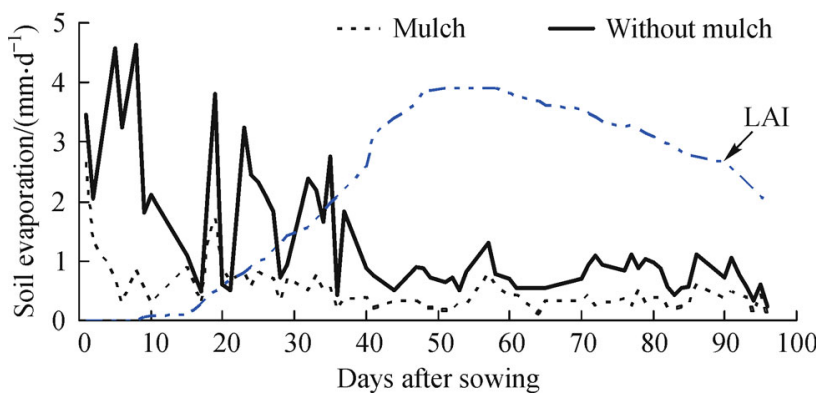

Fig. 6 The changes in daily soil evaporation with the leaf area index (LAI) for maize with and without mulch for a typical season at Luancheng station

Straw mulch on the soil surface also affects soil temperature which in turn influences crop growth, especially in winter crops. For maize, the summer crop, the mulch did not affect the crop development and yield. In contrast, with winter wheat the presence of straw on the soil surface reduced soil temperature during the period of critical development. From February to early April winter wheat is into recovery and jointing stages. During this time 
the average daily soil temperature $(0-10 \mathrm{~cm})$ was $0.42^{\circ} \mathrm{C}$ and $0.65^{\circ} \mathrm{C}$ lower under light and heavily mulched conditions compared to a non-mulched control. On average, over five seasons the lower soil temperature under mulch in spring delayed the development of winter wheat up to five days and reduced the final grain yield by $5 \%$ and $7 \%$ for light and heavily mulched treatments as compared with the control. After April with the increase in leaf area the effect of mulch on soil temperature gradually disappeared $^{[26,27]}$.

Although soil evaporation was reduced under mulch, yield of winter wheat was reduced. The overall WUE was not changed under straw mulching. It seems that under these experimental conditions the negative impact of delayed maturity was greater than any benefit of reduced evaporation from the soil surface. The negative effects of straw mulching to winter wheat need to be further studied and possibly combined with minimum irrigation or other treatments where water was a more serious limiting factor in grain production.

\section{Strategies to further increase WUE in future}

With intensifying water shortage and the increase in food demand with population growth in China, further increase in grain production will become more important. Further improvement in WUE and efficiently utilization of the limited water resources are important to mitigate the groundwater overdraft problem in the NCP.

\subsection{Full using the mechanisms underlying crop responses to water stress}

The mechanisms that underlay the responses of crops to water deficit involves many processes such as intercellular $\mathrm{CO}_{2}$, oxidative stress, sugar signaling, membrane stability and root chemical signals ${ }^{[28]}$. In water-limited environments, photosynthetic carbon gain and loss of water by transpiration are in a permanent tradeoff as both are oppositely regulated by stomatal conductance. Large unregulated fluxes of water are not essential to plant functioning and water can be saved by manipulating stomatal aperture. Future work will be required to continue focusing on understanding the factors that regulate the trade-off between carbon assimilation and water loss, and those that drive the partitioning of assimilates between reproductive and non-reproductive structures in relation to soil water availability. Rhizosphere manipulation, especially partial root-zone drying, root hydraulic resistance in response to nitrate supply and other methods to alter root to shoot signaling to regulate crop growth and water loss, will also be important factors to relieve the negative effects of water stress on crop yield.

\subsection{Further developments in deficit irrigation scheduling}

Deficit irrigation strategies are likely increasingly to be adopted around the world due to the water shortage problem $^{[28-30]}$. The responses of crops to water stress are affected by crop type, cultivar type and phenological stage as well as the crop growing conditions. With the frequent change in cultivars and growing environments of grain crops, the opportunities for applying deficit irrigation practices and related strategies need to be continuously investigated and developed to fit different practical situations.

Results showed that winter wheat can successfully be grown with deficit irrigation in the NCP. However, winter irrigation is still widely practiced in this region and is considered to compact the soil tillage layer for increasing the cold tolerances of winter wheat, particularly when straw from the previous crop is incorporated into the top soil. However, results from a previous study showed that the application of winter irrigation did not affect the growth and development of wheat in a normal season ${ }^{[31]}$. Winter irrigation increased soil evaporation during the long winter dormancy period and also increased water and nutrient leaching from the root zone which poses environmental risks. Further studies on the impacts of winter irrigation are still needed in order to provide management methods that farmers can adopt to replace these irrigation practices.

3.3 Supporting cultivation and management measures for new cultivars

Continual breeding of new cultivars has significantly improved grain production and WUE in China over the last three decades. Considering the vast population, limited arable land per farmer, the relative low education background and weak economical situation in rural area, the introduction of new cultivars is much easier than any other technologies in farming. Every year there are many new cultivars developed and sold on markets. However, farmers don't know which cultivar is more fitting to their conditions and what kinds of field management measures are required for a special cultivar. Studies are needed to focus on the traits of different cultivars that are beneficial to yield and WUE improvement ${ }^{[22,32-35]}$. Corresponding field management practices in irrigation, fertilizing and cultivation should be developed to bring out the yield and WUE potentials of the new major cultivars of winter wheat and maize in NCP.

3.4 Integrated measures to increase crop productivity under rain-fed condition

With less irrigation water available, irrigated arable land in the NCP might be changed to rain-fed land. Crop yield is 
generally lower and varies greatly from year to year under rain-fed condition, but results have shown that certain integrated management practices would significantly improve grain yield and crop water productivity under rain-fed condition. These measures include soil fertility improvement, ridge and furrow cultivation with plastic and straw mulching to harvest rainfall and conserve soil moisture, supplemental irrigation using small scale rainfall harvest system and so on ${ }^{[7,36]}$. This will make an important contribution to increase food production, while at the same time reducing irrigation water use.

For the NCP, the double cropping system of winter wheat and maize consumed more water than the water supply capacity of the region. Recommendations have been made to reduce the planting intensity, e.g., changing the two crops per year system to one crop per year or three crops every two years. The reduction in cropping intensity will reduce the field $E T$ and irrigation water use. However, optimized field management practices need to be developed to increase the grain production potential of the reduced cropping intensity. For example, for a single spring maize per year system in the NCP, the hightemperature at the grain-filling stage might be a limiting factor in increasing the yield potential of spring maize ${ }^{[37]}$. Integrated technologies are required to solve such problems.

\section{Conclusions}

The summary of the field studies at Luancheng station showed significantly improved yields and WUE for the past three decades. The major factors contributing to this improvement included the renewal of cultivars, regulated deficit scheduling, straw mulching, managing root systems for efficient soil water use and the increased soil fertility. The integrated measures could reduce irrigation water use by $60-120 \mathrm{~mm}$ annually, as compared with the local practice. However, the results were only tested at the experimental site, where soil fertility is relative higher and the soil water holding capacity is greater. The good soil condition plays an important role in the application of deficit irrigation scheduling of winter wheat. The results from this study might be suitable for areas in the NCP with similar soil conditions. For areas with different soil conditions, the measures discussed in this study might not be as effective.

Acknowledgements This research was supported by the Hebei S\&T Project (14227007D) and National Scientific Supporting Project (2013BAD05B02, 2013BAD05B05).

Compliance with ethics guidelines Xiying Zhang, Wenli Qin, and Juanna Xie declare that they have no conflict of interest or financial conflicts to disclose.

This article does not contain any studies with human or animal subjects performed by any of the authors.

\section{References}

1. Cheng H F, Hu Y N, Zhao J F. Meeting China's water shortage crisis: current practices and challenges. Environmental Science \& Technology, 2009, 43(2): 240-244

2. de Fraiture C, Wichelns D. Satisfying future water demands for agriculture. Agricultural Water Management, 2010, 97(4): 502-511

3. Li B, Peng S. Reports on agricultural water use in China from 1998 2007. Beijing: China Agriculture Publishing House, 2009 (in Chinese)

4. Zwart S J, Bastiaanssen W G M. Review of measured crop water productivity values for irrigated wheat, rice, cotton and maize. Agricultural Water Management, 2004, 69(2): 115-133

5. Zhang X Y, Pei D, Hu C S. Conserving groundwater for irrigation in the North China Plain. Irrigation Science, 2003, 21(4): 159-166

6. Li J. Water shortages loom as Northern China's aquifers are sucked dry. Science, 2010, 328(5985): 1462-1463

7. Deng X P, Shan L, Zhang H, Turner N C. Improving agricultural water use efficiency in arid and semiarid areas of China. Agricultural Water Management, 2006, 80(1-3): 23-40

8. Zhang X Y, Chen S Y, Liu M Y, Pei D, Sun H Y. Improved water use efficiency associated with cultivars and agronomic management in the North China Plain. Agronomy Journal, 2005, 97(3): 783-790

9. Zhang X Y, Chen S Y, Sun H Y, Wang Y M, Shao L W. Root size, distribution and soil water depletion as affected by cultivars and environmental factors. Field Crops Research, 2009, 114(1): 75-83

10. Zhang X Y, Chen S Y, Sun H Y, Shao L W, Wang Y Z. Changes in evapotranspiration over irrigated winter wheat and maize in North China Plain over three decades. Agricultural Water Management, 2011, 98(6): 1097-1104

11. Fang Q, Ma L, Yu Q, Ahuja L R, Malone R W, Hoogenboom G. Irrigation strategies to improve the water use efficiency of wheatmaize double cropping systems in North China Plain. Agricultural Water Management, 2010, 97(8): 1165-1174

12. Jensen C R, Orum J E, Pedersen S M, Andersen M N, Plauborg F, Liu F, Jacobsen S E. A short overview of measures for securing water resources for irrigated crop production. Journal Agronomy \& Crop Science, 2014, 200(5): 333-343

13. Zhang X Y, Chen S Y, Sun H Y, Wang Y M, Shao L W. Water use efficiency and associated traits in winter wheat cultivars in the North China Plain. Agricultural Water Management, 2010, 97(8): 11171125

14. Zhang X Y, Pei D, Chen S Y. Root growth and soil water utilization of winter wheat in the North China Plain. Hydrological Processes, 2004, 18(12): 2275-2287

15. Bonifas K D, Walters D T, Cassman K G, Lindquist J L. Nitrogen supply affects root:shoot ratio in corn and velvetleaf (Abutilon theophrasti). Weed Science, 2005, 53(5): 670-675

16. Wanga W, Ohse K, Liu J, Mo W, Oikawab T. Contribution of root respiration to soil respiration in a $\mathrm{C} 3 / \mathrm{C} 4$ mixed grassland. Journal of Biosciences, 2005, 30(4): 507-514

17. Wang Y Z, Zhang X Y, Liu X W, Zhang X, Shao L W, Sun H, Chen $S$. The effects of nitrogen supply and water regime on instantaneous WUE, time-integrated WUE and carbon isotope discrimination in winter wheat. Field Crops Research, 2013, 144: 236-244

18. Zhang X Y, Chen S Y, Sun H Y, Pei D, Wang Y M. Dry matter, 
harvest index, grain yield and water use efficiency as affected by water supply in winter wheat. Irrigation Science, 2008, 27(1): 1-10

19. Sun H Y, Zhang X Y, Chen S Y, Shao L W. Performance of a double cropping system under a continuous minimum irrigation strategy. Agronomy Journal, 2014, 106(1): 281-289

20. Zhang X Y, Pei D, Chen S Y, Sun H Y, Yang Y H. Performance of double-cropped winter wheat-summer maize under minimum irrigation in the North China Plain. Agronomy Journal, 2006, 98 (6): 1620-1626

21. Zhang X Y, Wang Y Z, Sun H Y, Chen S Y, Shao L W. Optimizing the yield of winter wheat by regulating water consumption during vegetative and reproductive stages under limited water supply. Irrigation Science, 2013, 31(5): 1103-1112

22. Liu X W, Zhang X Y, Chen S Y, Sun H Y, Shao L W. Subsoil compaction and irrigation regimes affect the root-shoot relation and grain yield of winter wheat. Agricultural Water Management, 2015, 154: 59-67

23. Zhang X Y, Shao L W, Sun H Y, Chen S Y, Wang Y Z. Incorporation of soil bulk density in simulating root distribution of winter wheat and maize in two contrasting soils. Soil Science Society of America Journal, 2012, 76(2): 638-647

24. Cresswell H P, Kirkegaard J A. Subsoil amelioration by plant rootsthe process and the evidence. Australian Journal of Soil Research, 1995, 33(2): 221-239

25. Rasse D P, Smucker A. Root recolonization of previous root channels in corn and alfafa rotations. Plant and Soil, 1998, 204(2): 203-212

26. Chen S Y, Zhang X Y, Pei D, Sun H Y, Chen S L. Effects of straw mulching on soil temperature, evaporation and yield of winter wheat: field experiments on the North China Plain. Annals of Applied Biology, 2007, 150(3): 261-268

27. Wang Y M, Chen S Y, Sun H Y, Zhang X Y. Effects of different cultivation practices on soil temperature and wheat spike differentiation. Cereal Research Communications, 2009, 37(4): 575-584

28. Chaves M M, Oliveira M M. Mechanisms underlying plant resilience to water deficits: prospects for water-saving agriculture. Journal of Experimental Botany, 2004, 55(407): 2365-2384

29. Fereres E, Soriano M A. Deficit irrigation for reducing agricultural water use. Journal of Experimental Botany, 2007, 58(2): 147-159

30. Geerts S, Raes D. Deficit irrigation as an on-farm strategy to maximize crop water productivity in dry areas. Agricultural Water Management, 2009, 96(9): 1275-1284

31. Shao L W, Zhang X Y, Sun H Y, Chen S Y, Wang Y M. Yield and water use response of winter wheat to winter irrigation in the North China Plain. Journal of Soil and Water Conservation, 2011, 66 (2): 104-113

32. Sadras V O, Lawson C. Nitrogen and water-use efficiency of Australian wheat varieties released between 1958 and 2007. European Journal of Agronomy, 2013, 46: 34-41

33. Kashiwagi J, Morito Y, Jitsuyama Y, An P, Inoue T, Inagaki M. Effects of root water uptake efficiency on soil water utilization in wheat (Triticum aestivum L.) under severe drought environments. Journal Agronomy \& Crop Science, 2015, 201(3): 161-172

34. Delzon S. New insight into leaf drought tolerance. Functional Ecology, 2015, 29(10): 1247-1249

35. Yang J C. Approaches to achieve high grain yield and high resource use efficiency in rice. Frontiers of Agricultural Science and Engineering, 2015, 2(2): 115-123

36. Rockström J , Barron J. Water productivity in rainfed systems: overview of challenges and analysis of opportunities in water scarcity prone savannahs. Irrigation Science, 2007, 25(3): 299-311

37. Wilhelm E P, Mullen R E, Keeling P L, Singletary G W. Heat stress during grain filling in maize: effect on kernel growth and metabolism. Crop Science, 1999, 39(6): 1733-1741 